\title{
9. Markets, Discipline, Students: Governing Student Conduct and Performance in the University
}

\author{
Bruce Lindsay
}

\section{Introduction}

The university has developed as a substantial and complex regulatory space in contemporary Australian society. Well over one million students are enrolled in the university system, in an environment that has assumed an increasingly commercialised character since the late 1980s. Market principles and norms have become prominent elements of higher education, under the influence of public policy, and hence, as a regulatory phenomenon, the market functions as a juridical and normative order. In this sense, the market is a governmental mechanism, having disciplinary effects.

This chapter takes a socio-legal view of the university system in the contemporary 'market order', and, in consideration of the disciplinary character of the market in relation to its mass student base, particular attention is paid to mechanisms for the regulation of student conduct and performance. Those mechanisms operate through schemes for student discipline and for academic sanction in circumstances of unsatisfactory academic progress. The present analysis considers how those schemes have evolved and adapted to the conditions of market governance in the university sector. 


\section{Market(s), discipline and governance}

It is a trite observation that the context in which governance of students now proceeds is heavily influenced, if not dominated, by market principles and models of behaviour. Marginson (1997a) has sought to theorise the rule of market arrangements in the sector, and operation of market mechanisms has coincided with the emergence of corporate ('enterprise') forms of the university as an institution (Marginson and Considine 2000), substantial modifications in expectations, behaviours, norms and legal treatment of students (notably toward experience as 'consumers'), and a treatment of the provision of higher education as an industry and as a major services sector.

The market system in which higher education now operates arguably does so at two levels.

The market in higher education is a market for 'educational services' (Larsen et al. 2002). The transaction at this level is a bargain for admission to the institution, for receipt of instruction, ancillary services and the benefit of collective knowledge and, upon successful exertions and completion (and payment of fees), the entitlement to an academic award (see Deech 2009; Moran $v$ University College Salford (No 2) [1994] ELR 187). The substitutable qualities of goods and services in this market (cf. Competition and Consumer Act 2010 (Cth), s 4E) are met in the competitive demand from students for places in the various institutions ('providers'), which in the language of Hirsch (1976) (and adopted by Marginson 1997; Marginson 2006), entail the 'positional good' of status, especially subsequent status or prestige in labour markets. Substitutable qualities of these markets are also met in the increasingly competitive supply arrangements of institutions, differentiation and contestability for students, especially in the course of accelerating policies of 'deregulation' and trends for public funding to follow student enrolments.

The market, however, not only operates at the level of the market for services; it also operates at the level of the circulation of capital. It is this sense of the autonomous circulation of knowledge, capacities, and intellectual practices as forms of economic and productive power that is captured in Lyotard's theory of the postmodern condition of knowledge (Lyotard 1984): that knowledge in general and, in respect of education, the figure of skill in particular, has assumed the quality of an independent economic-social force, dissociable from the 'training (Bildung) of minds' (Lyotard 1984, 4). Lyotard (1984, 4-5) noted nearly 30 years ago, the purpose of such 'performative' approaches to knowledge is the production and consumption of knowledge for commercial purposes and, in a wider sense, 'optimality' of the performance of social and economic systems (Lyotard 1984, 48). The commercial and performative logic of knowledge is less 
and less about ideals such as truth, or the 'cultivation' of the person (Bildung), or, as was more the Australian approach, the formation of the 'citizen-specialist' (Murray Report 1957, 7-11). Education now concerns knowledge objectified and valorised as an independent productive force; knowledge 'exteriorised with respect to the "knower"' (Lyotard 1984, 4). The student is a principal vehicle in the accumulation and optimisation of that force - and must be managed accordingly.

Lyotard did grasp the tendency of 'knowledge in the form of an informational commodity' to be treated as a marketable and saleable entity or object and for knowledge to be 'mercantilized' (Lyotard 1984, 5). But two further important points need to be considered in the development of the market and the industrial character of higher education. The first of these is that the autonomous economic force of knowledge acquires the form and character of capital. This notion that knowledge and competence acquired and reproduced in the higher education system is also to be conceived of as a distinct form of capital has achieved attention in the literature on 'cognitive capitalism' (e.g. Peters and Bulut 2011; Vercellone 2007; Federici and Caffentzis 2007; Boutang 2008). The analogy of 'human resources' and the student's accumulation of skills and competences as an 'extractable' base of saleable commodities is a somewhat simplified, but consistent, representation of his/her knowledge base as 'cognitive capital'.

In this respect, the industrialising character of higher education suggests two important spheres of transaction. First, the sphere of education and learning itself in which we might contemplate intellectual/cognitive transactions in the pedagogical sense: the processes of acquisition, inculcation, practice and reproduction of knowledge. The second sphere of transaction is the operation of the market at the level of the economic supply chain of skill, competence, knowledge - embodied in and co-produced with the student - and through which the higher education system supplies graduates onto the market for labour power. In particular, this transaction might be said to amount to the supply of professionalised labour power on to the labour market. 'Cognitive capital' is the 'package' or 'base' of certified and accumulated skills and competences embodied in the student (graduate); that is, certified by the university or other 'provider'.

Next, this market for the supply of cognitive capital, in which the university plays a central role, is, to borrow from Massimo De Angelis (2005), a dynamic and constitutive process, in which the construction of competence as an independent productive force is intrinsically combined with processes of valorisation and techniques of measure, and with the disciplinary techniques of the market. 
As De Angelis $(2005,72)$ notes: 'The immanent [capitalist] measure of value is constituted by the ongoing working of capitalist disciplinary processes (and therefore value struggles) passing through markets as well as their state implanted simulations.'

De Angelis and Harvey (2009) have considered these constitutive dynamics as applied to higher education in some detail. Higher education is invested with complex and layered forms of quantification and measure (valorisation), which realises and facilitates the 'market order'.

Thus, the market in higher education as a market for 'cognitive capital' involves an integrated circuit of (a) knowledge as an independent productive force (especially as manifest in the quantum of skills of the student/graduate), (b) the valorisation process and techniques of measurement, and (c) disciplinary processes, including processes of governance and regulation of students and institutions.

The market is disciplinary in its effects. At the 'macro' level, disciplinary power is exercised and deployed in techniques and norms framing, limiting and directing social relations. For instance, social relations within the university - teacher, student, administrator - are reproduced as economic actors, notably consumers and 'providers' in the supply chain. These tendencies to overarching, market-based normative discipline, especially in processes of 'economisation' (Marginson 1997b), have been considered at length as policy (Marginson 1997a) and juridical phenomena (e.g. Varnham and Kamvounias 2006).

The market also is disciplinary at the micro level - in its 'panopticonic' approach, as Foucault (1979, 195-228) famously described the sphere of disciplinary power. For higher education, the 'market order' operates in and through what De Angelis and Harvey $(2009,17)$ refer to as the 'fractal-panopticon', or the multiplicity of disciplinary and policing powers. 'Briefly,' they write:

the market-order as conceptualised by, for example, Friedrich Hayek, has organisational properties similar to that of Jeremy Bentham's 'panopticon'. These essentially disciplinary properties shaping social production are reproduced and extended throughout the social field and the planet. The panopticon of the global market is fractal in that different levels of social aggregation are self similar in terms of their disciplinary processes..

So within the framework of the overarching laws and norms of the market, including the singular juridical character of the student as consumer or as 'hybrid' institutional actor (cf. Rochford 1998), there exist within the university what Foucault $(1979,222)$ termed 'all those systems of micro-power that are essentially non-egalitarian and asymmetrical that we call the disciplines.' Foucault was looking to the real bases of control and ordering and 'panopticism 
constituted the technique, universally widespread, of coercion' (Foucault 1979, 222). Disciplinary techniques at this level constitute the basic sub-stratum of forces, mechanisms and arrangements for order. It is in this context that the question of the conduct and performance of students, and the regulatory mechanisms for their governance, should be situated. Zwagerman (2008), for example, has analysed university schemes for student discipline in terms of 'panopticism' in some detail. At the level of juridical character, it has been held that the formal legality of a student contract with the university may import the real complex of rules, regulations, policies and architecture of institutional order (Clark $v$ University of Lincolnshire and Humberside (2000) 1 WLR 1988; Bayley-Jones $v$ University of Newcastle (1990) 22 NSWLR 424).

The growth and intensification of market principles, rules and norms within higher education is also accompanied by expansion of formal rules and the juridical character of practices, dealings and relationships (Rochford 1998; Witteloostuijnand and de Jong 2007). This juridification of university life follows historic trends within other social and economic sectors, such as labour relations and social welfare. In higher education, the processes of juridification accord with the 'expansion and differentiation of law' into new spheres (Blichner and Molander 2008) and an incremental colonisation (cf. Wade 1969). Arguably, the process has accelerated in the recent decades of market reform. The growth of formal and semi-formal (e.g. administrative or 'soft law' (see Creyke 2010) regulatory systems governing higher education, as well as deployed by the university, is a key part of the disciplinary architecture of the "enterprise university' (Marginson and Considine 2000) and its underpinning economic model.

\section{The student}

The student is a central subject of governance in the university. At the empirical level, the student-university relationship has been characterised by certain defining trends. These include:

- eclipse of the student experience as a distinctive (pre-work) experience in the lifecycle and the integration of student experience with the labour force and family responsibilities (e.g. Devlin et al. 2008);

- fragmented and diverse student base, including substantial cohorts of older ('mature-aged'), off-campus students, students from lower socio-economic status backgrounds, and overseas students, especially from non-English speaking countries;

- the so-called disengagement of student from the institution (McInnis 2001), including decline of the campus as a site of activity; 
- long-term radical changes in pedagogical experience, including the revolution in online and technological mediation and sources of information and the construction of mass higher education on high volume programs, such as the rise in student-staff ratios (e.g. Bradley Report 2008, 72) and the casualisation of staff;

- the hegemony of economic models, commodity forms and consumer norms and expectations.

Governance of student subjects confronts the problem of a rapidly expanding, diversifying, anonymous, and technologically-mediated student base, operating in a radically new informational and intellectual landscape. These trends imply a managerial or technocratic 'student problem', of which issues of student conduct and performance - such as is the form of academic misconduct or unsatisfactory academic progress and attrition - form just one, albeit significant, dimension.

The process and discourse of governance is extensively influenced by administration. As Readings $(1996,152)$ argued, administration is now hegemonic and this includes the construction of the student as an administrative subject:

The administration of knowledge is, of course, the only point at which anything like a question of content enters: the question of what knowledge is to be managed by teachers and administered to students ... Teaching administers students. It accredits students as administrators, and it trains them in the handling of information. It probably does all these things rather successfully.

Administration is deeply insinuated into the logic and practice of academic life. Even if we limit observation to decisions that contain some element of academic judgment, administrative functions and procedures are prolific. Review of results, special consideration, complaint-handling, enrolments, reviews of higher degree by research students, extensions, course development and review, grading, peer-review decisions, disciplinary decisions and unsatisfactory progress, the awarding of degrees: all of these actions are administrative in character. They do not account for the mass of decisions made about fees, contracts, building works, finance, marketing, human resources, and so on.

Following Readings and Foucault, Alicia Evans (2011) has considered the effects of the pervasive qualities of administration on the Australian university, posing the student qua 'performer' within the administrative machinery, as against the student as an educational subject. The 'performative' character of the student, however, only partly grasps the changed subjective, disciplinary and governmental/administrative situation of the student in the 'market order'.

As Foucault (1979, 135-69) theorised, disciplinary techniques and powers, the apparatuses of administration and governance, are played out, unfold, and/or are applied to 'bodies', with the object of producing and reproducing 'docile 
bodies'. The purpose of governance or management is not simply repression. It is to render the 'body' useful and to achieve some form of optimality as well as utility. 'A body is docile that may be subjected, used, transformed and improved' (Foucault 1979, 136). For Foucault (1979, 165, 178-81, 186-87), the relevant 'docile body' representative of the educational sphere was that of the 'pupil'. That is arguably also the ideal student subject of the university system prior to the period of market and industrial transformation. The model of the pupil, subject to the mastery and authority of the tenured academician - the professorial ideal - was the guiding institutional relation in which disciplinary mechanisms operated. It is a discursive model that continued to relatively recent times:

The context of educational societies involves a special factor which is not present in other contexts, namely the relation of tutor and pupil; that is to say the society is charged with the upbringing and supervision of the pupil under tuition, be the society a university or college, or a school (Glynn $v$ Keele University (1971) 1 WLR 487, 494).

The 'body' to which the contemporary disciplinary forces of the market order apply is no longer the 'pupil', or youth in training to the academician. The fragmentation, diversity and complexity of the student base are evidence of a breakdown of that hegemonic, corporeal person.

Rather, the 'docile body' to which the university's governmental systems and controls now apply is a new type of person, perhaps best and most commonly expressed in the term 'learner' (see, for example,Candy et al. 1994), which is the student integrated directly into (at least in the virtual sense of functioning and acting within a broad simulation of) the workplace and labour market. Discourses of skill, employability, graduate attributes and academic performance are all integral to the 'body' of the student qua 'learner'. This new educational 'body' on which markets, institutions and regulatory machinery of higher education work is less the young person 'in formation', or the 'citizen-specialist' in training, than the burgeoning homo economicus. The model of the student is as an instrumental subject, acquisitive, a site of accumulation of professional skills and qualities. The person of the student becomes equated with a form of 'microfirm', an 'enterprise of oneself' (Marginson 1997b, 123), or 'basin of immaterial labour' (Lazzarato 1996, 136) within the cycle of professional work. Yet, given the increasing complexity and diversity of the student population, the 'body' of the student - that is, of the 'learner' - is to be measured, characterised and disciplined according to models and standards of conduct and performance. Foucault $(1979,181-83)$ notes that the disciplinary system is corrective and normalises (including for the pupil) a duality of sanction/punishment and privilege. This is productive of docility and utility. For the contemporary student, the ubiquitous 'learner', the system of reward and punishment and its 
disciplinary effects apply more to the 'cognitive body' than the physical body of the student (see, for example, Boni and Walker 2013). The governance of the 'cognitive body' of intellectual capacities and behaviours is, in this sense, parallel to Nikolas Rose's reading of the regulation of self and subjectivity as 'governing the soul' (Rose 1990). That is, the rationality of academic systems, now pervasively inculcated and moulded to administrative systems (Readings 1996; Evans 2011), is the science and practice of governing the higher cognitive powers of the individual.

\section{The regulatory system for student discipline and academic exclusion}

Universities have regulatory powers for the governance of student conduct ('student discipline') and academic performance ('unsatisfactory progress'). These are formalised, quasi-judicial procedures that can provide the basis for termination of a student's status as such and even, collaterally, their right to be in the country, given visa conditions requiring enrolment and satisfactory academic progress. Other than voluntary withdrawal or graduation, these are the sole means of severing a student's status and relationship with the university. The consequences of adverse decisions can be grave, although there are many levels of intervention and/or sanction in this sphere short of exclusion from the institution.

For the sake of context, it is useful to distinguish these quasi-judicial mechanisms of university governance and regulation from the wider academic-administrative terrain of 'everyday' governance of students. Within the university, the masses of decisions and institutional actions that are disciplinary in the discursive sense are those such as decisions of routine academic judgment, assessment, grading and allocation of students thereby to an intellectual hierarchy. This is a process of ordering and classifying cognitive powers and abilities, according to the frameworks of academic programs, 'learning outcomes', assessment procedures, systems and codes of knowledge. This is not to suggest an absence of countervailing norms, practices and communities in the wide sphere of academic discretion (including matters of assessment, pedagogy and administration) (see, for example, Harvey 2004; Lambert et al. 2007). But these latter forces, while potentially turbulent, innovative or resistant, remain presently confined and marked by overarching disciplinary frameworks.

Powers of student discipline and sanction for sustained poor academic performance might be said to be secondary regulatory powers, which is to say action available subsequent to decisions such as those of 'pure' academic judgment. Other than for actions in response to 'non-academic' misconduct, 
these secondary powers are typically dependent on primary academic decisionmaking. Primary powers are those exercised either to establish the programs, standards and decision-making frameworks of the academy (e.g. courses, rules, pedagogical techniques, intellectual norms), or those, as noted above, deployed to assess and evaluate the performance of students and their exercise of intellectual/cognitive abilities (e.g. academic judgment, grading, certification).

Schemes for student discipline and unsatisfactory progress have long been held to be subject to judicial supervision (University of Ceylon $v$ Fernando (1960) 1 All ER 631; $R v$ Aston University Senate; ex parte Roffey (1969) 2 WLR 1418; Glynn $v$ Keele University (1971) 1 WLR 487) and, whether operating on the basis of a student contract or the university's administrative-legal authority over its 'members' (including students), institutional conduct under such schema is subject to the ordinary legal norms of fairness, rationality and lawfulness (see also Simjanoski $v$ La Trobe University [2004] VSC 180; Bray $v$ University of Melbourne [2001] VSC 391; X v University of Western Sydney (No. 3) [2013] NSWSC 1329; Bell v Victoria University of Wellington [2010] NZHC 2200).

Both student disciplinary schemes and academic progress schemes, therefore, adhere to certain basic procedural requirements of fairness and impartial decision-making. There will be a form of 'tribunal' - usually in the form of committee or panel - charged with conducting a hearing, before which the student may make submissions and call evidence (see generally Lindsay 2008b). Disciplinary scheme are ordinarily accompanied by an express disciplinary code. Academic progress rules will turn on certain rules or thresholds of 'satisfactory' progress. Further points on each body of rules are noted below.

Prior to the period of 'mass' higher education, the smaller, elite enclaves of universities in Australia (as in, for instance, the UK) tended to combine general, informal supervision and management of students, under customary academic codes and norms, with occasional, formalised disciplinary or exclusionary arrangements. From the 1960s, there were pressures to adopt reasonably formal, quasi-judicial procedure (see, for example, Forbes 1970-71). These levels of formality were perhaps also a residue of the magisterial authority held by vice-chancellors in the ancient English universities (see, for example, CrippsDay 1894). This stark dichotomy between general informality and occasional formal procedure was perhaps also consistent with the circumstances of the universities as small 'educational societies', or voluntary institutions analogous to self-governing 'social clubs' (see $R v$ Aston University Senate; ex parte Roffey (1969) 2 WLR 1418).

Contemporary regulation of student conduct and performance represents a break with older, more paternalistic models of the university and past concerns in relation to student supervision (see Lindsay 2008a). Contemporary approaches 
are reflective of the industrial character of the institution, as discussed above, and the reproduction of market discipline and regulatory measures applying to the 'cognitive body' of the student.

\section{Student discipline and misconduct}

Contemporary concerns with misconduct have generally focused on academic misconduct, such as plagiarism or collusion or exam cheating. There is a growing number of studies investigating motivations and behaviours relating to misconduct, which suggest high rates of transgressive behaviour or at least, arguably, a high level of non-conformity with academic norms (e.g. FranklynStokes and Newstead 1995; De Lambert et al. 2006; Marsden et al. 2005; Norton et al. 2001).

In a study of seven Australian universities, it was found, on average, around one per cent of enrolled students in the sample were subject to some kind of disciplinary action for misconduct (Lindsay 2010). The overwhelming majority of cases involved allegations and/or findings of academic misconduct, such as plagiarism or exam cheating. Recent media reports suggest that cases of formal misconduct in Western Australian universities are in the hundreds, if not thousands, and largely concern forms of academic misconduct (Hiatt 2013).

In relation to student misconduct, there has been an historic shift by institutions in the manner of engagement with students over issues such as plagiarism, collusion and use or misuse of the information technologies. This shift has been variously panoptoconic (Zwagerman 2008) and militant (Zobel and Hamilton 2002; Briggs 2003). Three main techniques are evident. First, there has been widespread use and adoption of so-called plagiarism detection software such as Turnitin. Use of these technologies may be a precursor to marking of papers, or available where any suspicion arises as to 'originality' of work. Notwithstanding problems that may arise with concepts of 'originality' in students' work (Richardson 2002; Chandrasoma 2004), these technologies are now key means of surveillance over students' intellectual output (Zwagerman 2008). They may also now be used as means of student self-policing and surveillance, whether as a basis of fear or threat to students or to be used directly by them to verify and analysis the 'originality' of their own work.

Secondly, alongside 'back end' technologies of surveillance and the prospects of punitive action, universities have undertaken concerted 'educative' campaigns, aimed at circumventing academic-disciplinary problems. These range from provision of notices prior to submission of student work or prior to exams, 
online warnings, dedicated 'practical skill' training sessions in academic norms and conventions, and development of 'academic skills' programs and staff, especially (but not exclusively) for international students.

Thirdly, as in common with regulatory approaches to the policing of norms, universities apply graduated and proportionate responses to transgressions. This may have informally applied previously but no doubt the present scale of academic-disciplinary issues has led to more formalised guidance and rules. Graduated action ranges from clearly punitive responses to cases of intentional and/or calculated misconduct (e.g. exclusion) to educative or pastoral approaches at the marginal end of the spectrum where, for example, poor writing or expression skills may be at issue (e.g. warnings, resubmission of work) (see, for example, Deakin University Student Academic Misconduct Procedure, Schedule A).

\section{Academic progress}

Rates of exclusion or other remedial action by institutions for poor student performance appear not to be commonly reported or available (Department of Education, Employment and Workplace Relations 2011; Wimhurst et al. 2006, 133-34). However, student attrition and progress rates are known. 'Attrition' and 'progress' indicators combine various factors, including failure, withdrawal, and course transfers, hence are only a very rough guide to exclusion for poor performance. Over the 2001-09 period, student progress rates for all undergraduate students have remained stable and attrition rates (student nonreturn to study) have fallen. Student progress rates were around 85 per cent in 2009 (i.e. around 15 per cent of students failed or withdrew) (Department of Education, Employment and Workplace Relations 2011).

There are grounds to argue that actions for poor academic performance are more prolific than for student discipline. Part of the reason for the occurrence of academic exclusion is that it is a routine extension of the academic process and typically triggered by numerical thresholds: for example, when a student fails (receives a grade of less than 50 per cent) in a fixed number of subjects, a process for review and decision-making on the basis of academic performance is triggered. Also, disciplinary processes are accusatorial and arguably attract a greater level of opprobrium.

Institutional responses to rates of exclusion for poor academic performance now include pre-emptive and graduated strategies (e.g. University of Melbourne Academic Performance Policy, cl 2). Pre-emptive strategies include early identification of students considered to be 'at risk' of later exclusion for poor performance; for example, where a student fails a substantial number of 
subjects in a particular semester, especially early-year students (University of Melbourne Academic Progress Review Procedure, cl 7). Adoption of the language of risk implies, in this instance, a problem applicable both to the individual student, manifest for example in external issues impacting on performance as well as intellectual shortcomings, and applicable to the institution insofar as accumulations of failing grades reflect on the reputation of the university in the market.

As with disciplinary practices, graduated responses to poor student performance typically span exclusion from the university, re-enrolment conditional on meeting prescribed performance targets, and re-enrolment accompanied by provision of pastoral or academic assistance or advice.

Overseas student regulation now influences institutional approaches to academic performance, requiring systematic approaches to early intervention and hence ongoing monitoring or performance (National Code of Practice for Registration Authorities and Providers of Education and Training to Overseas Students 2007 (Cth), Standard 10). Institutions enrolling overseas students have express surveillance obligations, given further effect by their function in migration regulation, such as in requirements to certify that student visa holders have achieved satisfactory academic performance (or not, as the case may be) (Education Services for Overseas Student Act 2000 (Cth), ss 19(2); Migration Regulations 1994 (Cth), Schedule 8, Condition 8202(3)).

Regulatory influences on misconduct and progress procedures have increased over the past decade. This includes direct influence, such as for 'at risk' intervention strategies and codification of appeals and review, as well as the indirect influence of pervasive and far-reaching regulation of the sector generally, especially 'consumer protection'-type regulation (e.g. Education Services for Overseas Students Act 2000 (Cth); Baird Report 2010, 5) and institutionalisation of an academic 'quality assurance' regime. Further, methods of academic policing of students have become far more systematic and explicit, especially in the use of technological surveillance, early-intervention procedures and the rhetoric of risk (e.g. Tertiary Education Quality and Standards Agency Act 2011 (Cth), s 15), transgression, and anxiety (Zwagerman 2008, 683-86). Finally, universities have developed a range of 'soft' techniques aimed at ordering, organising and influencing conduct and performance (see, for example, McInnis 2003). These are more akin to 'welfare' measures and include, for instance, substantial counselling, welfare and academic 'advisory' staff. 


\section{The evolution of purposes for regulatory controls over student conduct and performance}

The market-disciplinary character of university surveillance of, and powers over, student conduct and performance reflects the now dominant industrialeconomic project of higher education. The policing mode of these powers is a strategic response to these conditions and the multifaceted 'student problem'.

\section{Confidence in the supply chain of cognitive capital}

First and foremost, this 'problem' is the student as bearer of 'cognitive capital', as the 'cognitive subject', and consequently the problem of supply of cognitive capital onto the labour market. Student discipline and academic progress, in their contemporary focus on academic 'integrity', 'standards' and performance, contribute significantly to the discourse and practice of institutional 'quality' and cultures of audit and surveillance entailed in these agenda. These are approaches now incorporated into statutory form (see, for example, TEQSA Higher Education Standards Framework (Threshold Standards) 2011 (Cth), ss 4, 6), although reflective of the extensive machinery of 'quality assurance' now well-established in the higher education sector (e.g. Harman 1994; Vidovich 2002; Shah et al. 2011). The actuarial discourse of 'assurance' and 'risk' was emphasised in the Bradley Review for instance (Bradley Review, [4.1]). As noted above, it underpins the approach of the sectoral regulator (Tertiary Education Quality and Standards Agency Act 2011 (Cth), s 15; TEQSA Regulatory Risk Framework). 'Risk' reveals the sentiment that in the student - at least in their objectified behaviours and intellectual practices - there is the spectre of threat. It is a multifold threat: of transgression, incapacity (incompetence) and/or reputational damage. The threat may be manifest in immediate modes of crisis, such as in reputational damage of the institutional 'product' in the market (see, for example, Victorian Ombudsman 2010; Victorian Ombudsman 2011; Independent Commission Against Corruption 2005), or longer-term senses of secular crisis (Senate Education, Employment and Workplace Relations Committee 2001, Chapter 5). Regulation and policing of conduct and performance is one important dimension of dealing with the question of market and state confidence (see, for example, Bradley Review, [4.1]). 


\section{Response to motivational crisis}

The second basis for emergence of the policing mode on the part of higher education institutions relates to the subjective crisis of the student. While there have always been rates of student misconduct and non-performance, the present context is heavily influenced by the disjuncture between instrumental goals attached to knowledge, performance and learning (e.g. grades, qualifications) and intellectual norms (e.g. academic ethics).

In part, this phenomenon might represent a rupture in older organising principles in the university, such as relatively stable intellectual communities, campus experience and the professional acculturation process of university life. Student 'disengagement' or 'negotiated engagement' (McInnis 2001) is a complementary symptom of the wider subjective reorganisation.

Clearly, there is engagement by students in higher education. It is really the nature of that engagement and the values, expectations, discourse and norms underpinning it that is at issue. The question is the extent to which higher education is primarily, or even substantially, a self-determining intellectual exercise (as the Bildung or 'citizen-specialist' models presupposed), or rather the postmodern experience in which the student, reduced to being the manager of their accumulated skills, competence and motivations within a highly transactional (provider-consumer) relationship, is a sort of highly competent and strategic game-player. Arguably, the horizon of the student is deeply pragmatic and may be subject to substantial external forces and pressures (e.g. Victorian Ombudsman 2011, [234]).

Students are not amoral. Rather, there are contradictory and complex rationalities and pressures at issue, including acquisition and adherence to norms, uncertainty or instability in those norms, high-stakes outcomes, and complex practical realities and opportunities (see, for example, Sattler et al. 2013; Maher et al. 2009). Additionally, the university as the source and mediator of intellectual knowledge - including the authority as to technique (e.g. 'critical and independent thought' (Higher Education Standards Framework (Threshold Standards) 2011 (Cth), s 4.1) and norms of its acquisition (e.g. academic conventions) - are under challenge from the saturation of knowledge in electronic sources and possibly from the trend of some institutions to mass, relatively indiscriminate delivery (e.g. MOOCs).

If the motivating force of students' relationship with the university (and its governing intellectual project) is under challenge, external discipline and policing modes, as distinct from internalised self-discipline, arguably step into the breach - to the extent they provide alternative motivating forces. These may be negative, such as in terms of fear of exclusion or disciplinary action. 
Or they may be positive, in the ranks of advisers, counsellors, facilitators, 'early intervention' programs and other 'support services' - all deployed to guide students and optimise performance and results.

\section{Managing permanent crisis and selective austerity}

Finally, policing approaches serve as a response to long-term ('secular') dynamics of institutional crisis, especially evident in austerity and applied to teaching and learning (the pedagogical space). Informal policing of standards was, from a practical point of view, a viable strategy in smaller, close-knit, sometime paternalistic institutions. The erosion of such conditions is indicated in, for instance, the comparison of staff to student ratios over a 60-year period. University statistics in the 1950s showed ratios between 1:3 and 1:12 (Murray Report 1957, 39-40). Vice-chancellors at the time apparently complained that Australia was not comparable with the UK, where ratios were around 1:7. By the 2000s, those ratios were approximately 1:20 and have steadily risen since the late 1980s (Universities Australia 2006). Concurrently, there have been longterm constraints on funding to resources such as libraries and long-term shifts in the academic workforce toward casualisation and increased work intensity. The constraints on teaching and learning noted by the Senate Employment, Workplace Relations and Education Committee (2000, [5.55]-[5.68]) more than a decade ago are unlikely to have improved fundamentally in the meantime.

The policing function is a response to austerity at two levels. It displaces the proportionately declining institutional space of teaching with technological, regulatory and/or therapeutic ('student support') machinery. It also is practically and logically consistent with the shift toward administration.

\section{Conclusions}

The administrative and regulatory technologies of the university are also technologies of the market. Quasi-judicial mechanisms applying to student discipline and academic progress are particular models of academic administration crafted in the shadow of law and with procedures mimicking or adapted from legal models. They are now applied and adapted to an institutional, cultural and epistemological terrain profoundly changed over the course of several decades. This chapter has argued that these mechanisms need to be viewed in the context of the industrial and economic revolution in which the central productive force of the university - knowledge manifest in the cognitive and intellectual powers of the student - assumes a strategic role in capital accumulation. It is well to argue, from the perspective of law, that regulatory mechanisms for the governance of student conduct and performance should be applied fairly and 
with real adherence to principles of formal justice (e.g. Lindsay 2012a; 2012b). If we take a deeper view, from the perspective of social and cultural theory and radical political economy, juridical concepts of justice are only part of the equation. Governance, administration and law in the university need to (re) consider and engage critically with the models and forms of education and knowledge - that is, function beyond (and against) the models and conditions of capital. If that is to be achieved, universities will also need to think beyond functions and techniques of academic policing (see, for example, Chandrasoma 2004) and in resistance to the market. 
This text is taken from Through a Glass Darkly: The Social Sciences Look at the Neoliberal University, edited by Margaret Thornton, first published 2014, this version 2015 by ANU Press, The Australian National University, Canberra, Australia. 